\title{
Peningkatan hasil belajar Pendidikan Kewarganegaraan (PKn) pada peserta didik kelas 3 SDN 02 Talun melalui media CD interaktif
}

\author{
Darsono \\ SD Negeri 02 Talun Kec. Talun Kab. Pekalongan
}

\begin{tabular}{|c|c|}
\hline Article Info & ABSTRACT \\
\hline Article history: & \multirow{3}{*}{$\begin{array}{l}\text { This study aims to improve the students' story writing skills and increase the } \\
\text { Citizenship Education (Civics) as a tool for maturation for students with a } \\
\text { conscious and planned effort through learning so that changes occur in these } \\
\text { students related to national knowledge, attitudes, and behavior. The purpose } \\
\text { of this study was to improve the learning outcomes of Citizenship Education } \\
\text { (Civics) in 3rd grade students of SDN } 02 \text { Talun through interactive CD } \\
\text { media. This type of research is Classroom Action Research (CAR) with four } \\
\text { stages, namely planning, action, observation and reflection. In this study, two } \\
\text { research cycles were conducted. The subjects in this study were } 19 \text { students } \\
\text { of SDN } 02 \text { Talun, Pekalongan Regency. Data collection techniques in this } \\
\text { study are observation, tests, documentation and interviews. The success } \\
\text { indicator in this study is for individual learning completeness if the } \\
\text { proportion of students' correct answers is more than the predetermined KKM } \\
\text { and for classical learning completeness if at least } 85 \% \text { of all students have } \\
\text { reached the KKM. The results of this study for the first cycle of classical } \\
\text { completeness reached } 73.68 \% \text { with } 14 \text { students who reached the KKm. } \\
\text { While in cycle } 2 \text {, classical completeness reached } 89.47 \% \text { with } 17 \text { students } \\
\text { who reached the KKM. So that in cycle } 2 \text { the success indicator is achieved. }\end{array}$} \\
\hline $\begin{array}{l}\text { Received : } 27 \text { Juli } 2021 \\
\text { Revised : } 25 \text { September } 2021 \\
\text { Accepted : } 28 \text { September } 2021\end{array}$ & \\
\hline $\begin{array}{l}\text { Keywords: } \\
\text { interactive } \mathrm{CD} \text {; learning } \\
\text { outcomes; media }\end{array}$ & \\
\hline
\end{tabular}

(*) Corresponding Author:

darsonotalun02@gmail.com

How to Cite: Darsono, D. (2021). Peningkatan hasil belajar Pendidikan Kewarganegaraan (PKn) pada peserta didik kelas 3 SDN 02 Talun melalui media CD interaktif. Action Research Journal, 1(1): 71-75.

\section{PENDAHULUAN}

Permendiknas No. 22 Tahun 2006 Tentang Standar Isi Kurikulum Nasional menyatakan mata pelajaran Pendidikan Kewarganegaraan (PKn) ditingkat SD/MI bertujuan agar peserta didik memiliki kemampuan: (1) Membentuk peserta didik menjadi manusia yang beriman dan bertaqwa kepada Tuhan Yang Maha Esa; (2) Berpikir secara kritis, rasional, dan kreatif dalam menanggapi isu kewarganegaraan; (3) Berpartisipasi secara aktif dan bertanggung jawab, dan bertindak secara cerdas dalam kegiatan bermasyarakat, berbangsa dan bernegara, serta antikorupsi; (4) Berkembang secara positif dan demokratis untuk membentuk diri berdasarkan karakter masyarakat Indonesia agar dapat hidup bersama dengan bangsa lain; ( 5) Berinteraksi dengan bangsa lain dalam percaturan dunia baik secara langsung maupun tidak langsung dengan memanfaatkan ilmu dan teknologi. Mengingat begitu pentingnya mata pelajaran PKn, maka diajarkan ke peserta didik mulai dari kelas 1 SD.

Mulyaningrum dan Andi Rivai (2009) menyatakan mata pelajaran PKn difokuskan pada pembentukan karakter peserta didik dalam memahami dan melaksanakan hak serta kewajiban sebagai warga negara Indonesia yang cerdas, terampil, dan berkarakter yang diamanatkan oleh Pancasila dan UUD 1945. Sementara Sofhian dan Asep Sahid (2011) menyatakan PKn sebagai salah satu alat untuk pendewasaan bagi peserta didik dengan usaha sadar dan terencana melalui pembelajaran sehingga terjadi perubahan pada peserta didik tersebut terkait pengetahuan, sikap, dan perilaku yang berkebangsaan. 
Namun, dalam praktik pembelajaran peserta didik sering kali mengalami kesulitan dalam menyelesaikan soal terkait dengan mata pelajaran PKn. Berdasarkan hasil prasurvey yang telah dilakukan, hasil belajar peserta didik kelas 3 SDN 02 Talun masih belum mencapai Kriteria ketuntasan Minimal (KKM). Sebagaimana disajikan pada Tabel 1.

Tabel 1. Hasil Prasurvey Mata Pelajaran PKn pada Peserta Didik Kelas 3 SDN 02 Talun

\begin{tabular}{ccccc}
\hline No. & Nilai & Kriteria & Jumlah peserta didik & Persentase \\
\hline 1 & $<75$ & Belum tuntas & 8 & $42,11 \%$ \\
2 & $\geq 75$ & Tuntas & 11 & $57,89 \%$ \\
& \multicolumn{2}{c}{ Jumlah } & 19 & $100,00 \%$ \\
\hline
\end{tabular}

Dari Tabel 1 terlihat bahwa hasil belajar peserta didik masih banyak yang belum mencapai KKM. Masih terdapat 11 peserta didik dengan persentasi 57,89\% yang belum mencapai KKM. Untuk itulah diperlukan solusi agar dapat meningkatkan hasil belajar peserta didik mata pelajaran PKn. Salah satu solusi yang diharapkan dapat meningkatkan hasil belajar peserta didik adalah penggunaan media yang inovatif. The Association for Educational Communication and Technology (AECT) dalam Asyhar (2012) menyatakan media adalah apa saja yang digunakan untuk menyalurkan informasi. Media merupakan alat yang digunakan untuk menyalurkan pesan dan informasi. Sudjana dan Rivai (2007) menyatakan media adalah teknologi pembawa pesan yang dapat dimanfaatkan untuk keperluan pembelajaran. Media pembelajaran mencakup semua sumber yang diperlukan untuk melakukan komunikasi dalam pembelajaran termasuk pendidik. CD interaktif merupakan sebuah media yang dikemas dalam sebuah CD dengan tujuan aplikasi interaktif di dalamnya. CD interaktif merupakan salah satu hasil implementasi dari multlimedia dimana terdapat hampir semua konten multimedia yaitu, gambar, video, animasi, text pengolahan/editing, serta pemberian navigasi untuk menjalankan CD tersebut (Sasongko, 2013). Dari uraian di atas, tujuan dari penelitian ini adalah untuk meningkatkan hasil belajar Pendidikan Kewarganegaraan (PKn) pada peserta didik kelas 3 SDN 02 Talun melalui media CD interaktif.

\section{METODE}

Tempat penelitian ini dilaksanakan di SDN 02 Talun Kabupaten Pekalongan. Subjek pada penelitian ini adalah peserta didik kelas 3 SDN 02 Talun Kabupaten Pekalongan dengan total 19 orang. Waktu pelaksanaan penelitian ini adalah semester gasal tahun ajaran 2020/2021. Jenis penelitian ini adalah Penelitian Tindakan Kelas (classroom action research) yang terdiri dari empat tahapan.

1. Perencanaan

Pada tahap ini, peneliti membuat $\mathrm{CD}$ interaktif sesuai dengan materi yang disampaikan, merencakan skenario pembelajaran dengan membuat RPP, menyusun lembar observasi peserta didik, lembar kerja peserta didik dan lembar aktivitas peserta didik, dan menyusun soal tes

2. Pelaksanaan

Pada tahap ini, dilaksanakan pembelajaran sesuai dengan RPP yang telah disusun dengan menerapkan media pembelajar CD interaktif

3. Observasi

Pada tahap ini, peneliti mengamati respon peserta didik terhadap pembelajaran menggunakan CD interaktif

4. Refleksi

Pada tahap ini, peneliti menganalisis hasil pembelajaran menggunakan media CD interaktif, menganalisis hasil pengamatan dan membuat simpulan sementara terhadap pelaksanaan siklus 1 serta mendiskusikan hasil analisis tindakan perbaikan pada siklus 1 untuk dilanjutkan pada siklus 2 jika indikator ketercapaian belum terpenuhi. 
Teknik pengumpulan data pada penelitian ini yaitu observasi, tes, dokumentasi dan wawancara. Untuk teknik analisis data dilihat dari jumlah peserta didik yang mengalami peningkatan hasil belajar, yang diperoleh dari siklus 1 dan siklus berikutnya.

1. Nilai rata-rata

Nilai rata-rata peserta didik dihitung dengan menggunakan rumus:

$$
\begin{aligned}
& X=\frac{\sum X}{N} \\
& \text { Keterangan } \\
& X \quad=\text { nilai rata-rata } \\
& \sum X=\text { jumlah nilai peserta didik } \\
& N \quad=\text { jumlah peserta didik }
\end{aligned}
$$

2. Ketuntasan klasikal

Ketuntasan klasikal merupakan nilai dari hasil belajar tiap siklus secara keseluruhan setelah proses pembelajaran menggunakan media CD interaktif.

$$
\text { Persentase }=\frac{\text { Jumlah peserta didik yang mencapai KKM }}{\text { Jumlah seluruh peserta didik }} \times 100 \%
$$

Indikator keberhasilan pada penelitian ini adalah untuk ketuntasan belajar individu jika proporsi jawaban benar peserta didik lebih dari KKM yang telah ditetapkan dan untuk ketuntasan belajar klasikal jika minimal 85\% dari seluruh peserta didik telah mencapai KKM.

\section{HASIL DAN PEMBAHASAN}

Nilai post test mata pelajaran PKn pada peserta didik kelas 3 SDN 02 Talun diperoleh dari siklus 1 dan siklus 2. Evaluasi pada setiap siklus dilakukan menggunakan instrumen soal

\begin{tabular}{|c|c|c|c|c|}
\hline No. & Nilai & Kriteria & Jumlah peserta didik & Persentase \\
\hline 1 & $<75$ & Belum tuntas & 14 & $73,68 \%$ \\
\hline 2 & $\geq 75$ & Tuntas & 5 & $26,32 \%$ \\
\hline \multicolumn{3}{|c|}{ Jumlah } & 19 & $100,00 \%$ \\
\hline
\end{tabular}
sebanyak 10 soal. Soal tersebut diberikan setelah proses pembelajaran menggunakan media CD interaktif. Karena masih pandemi Covid-19, maka proses pembelajaran berlangsung secara daring. Siklus 1 dilaksanakan pada 7 September 2020 s.d. 18 September 2020, untuk siklus 2 dilaksanakan pada 21 September 2020 s.d. 2 Oktober 2020.

Tabel 2. Hasil Belajar PKn Peserta Didik Kelas 3 SDN 02 Talun untuk Siklus 1

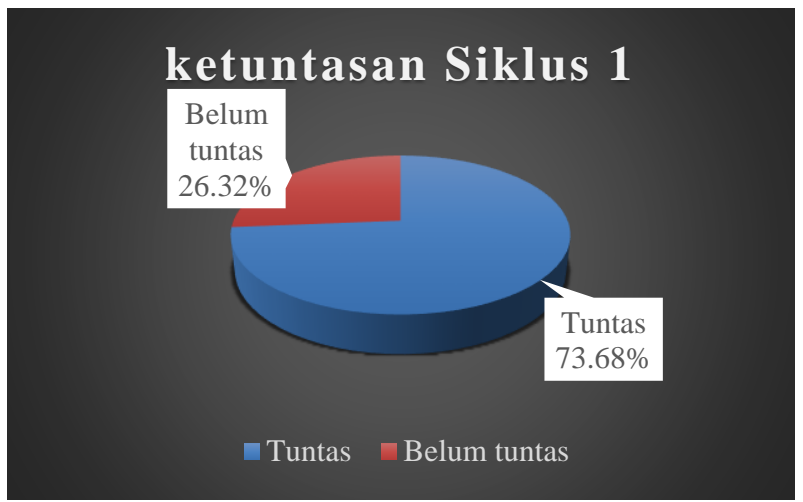

Diagram 1. Ketuntasan Belajar Peserta Didik Pada Siklus 1

Berdasarkan tabel dan diagram diatas, jumlah peserta didik yang telah mencapai KKM ada 14 orang dengan persentase $73,68 \%$, sementara jumlah peserta didik yang belum mencapai KKM berjumlah 5 orang dengan persentase $26,32 \%$. Artinya persentase tersebut belum mencapai indikator keberhasilan yang ditetapkan yaitu sebesar $85 \%$ dari seluruh peserta didik mencapai nilai KKM. Untuk itulah pada penelitian dilakukan siklus 2. Data hasil siklus 2 ditunjukkan pada Tabel 3. 
Tabel 3. Hasil Belajar PKn Peserta Didik Kelas 3 SDN 02 Talun untuk siklus 2

\begin{tabular}{ccccc}
\hline No. & Nilai & Kriteria & Jumlah peserta didik & Persentase \\
\hline 1 & $<75$ & Belum tuntas & 17 & $89,47 \%$ \\
2 & $\geq 75$ & Tuntas & 2 & $10,53 \%$ \\
& Jumlah & 19 & $100,00 \%$ \\
\hline
\end{tabular}

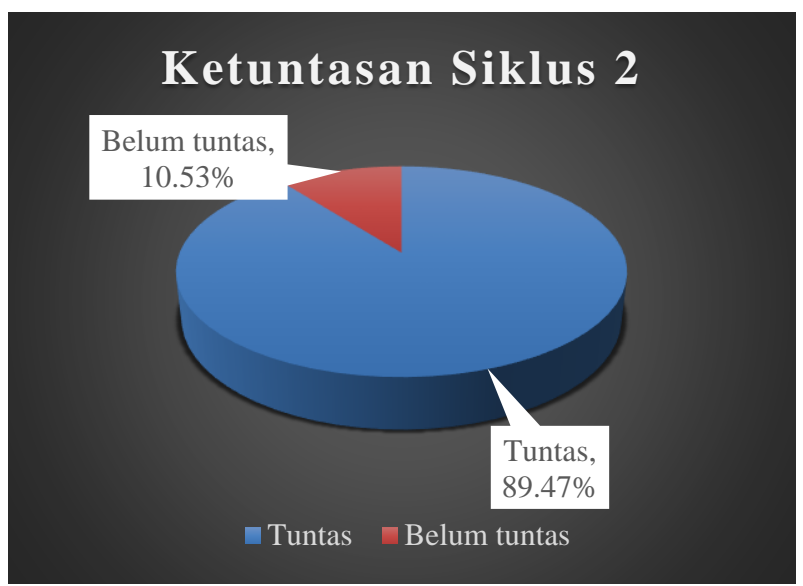

Diagram 2. Ketuntasan Belajar Peserta Didik pada Siklus 2

Berdasarkan tabel dan diagram diatas, jumlah peserta didik yang telah mencapai KKM ada 17 orang dengan persentase $89,47 \%$, sementara jumlah peserta didik yang belum mencapai KKM berjumlah 2 orang dengan persentase 10,53\%. Artinya persentase tersebut sudah mencapai indikator keberhasilan yang ditetapkan yaitu sebesar $85 \%$ dari seluruh peserta didik mencapai nilai KKM. Untuk itulah tidak diperlukan siklus 3.

Peningkatan hasil belajar pada siklus 1 dan siklus 2 sangat signifikan. Hal ini dikarenakan ketika proses pembelajaran menggunakan media CD interaktif, peserta didik sangat antusias dalam kegiatan tersebut. Hal ini sesuai dengan pendapat Suprapto (2006) bahwa pemakaian media pembelajaran sangat membantu dalam kegiatan pembelajaran khususnya pada sekolah dasar. CD interaktif membantu peserta didik dalam format multimedia yang dikemas dalam sebuah CD dengan tujuan aplikasi interaktif didalamnya (Sasongko, 2013). Hayumuti (2016) menyatakan CD interaktif menggunakan desain yang efektif meliputi teks, suara, gambar, foto, ilustrasi, animasi, video dan lainnya sehingga minat peserta didik akan meningkat. Selain meningkatkan antusias dan minat, dari hasil pengamatan juga terlihat bahwa pembelajaran menggunakan $C D$ interaktif juga meningkatkan daya tarik dan motivasi peserta didik dalam belajar. Hal tersebut sesuai dengan pendapat Rahayuningsih (2012) bahwa Salah satu keunggulan dari penggunaan $C D$ interaktif yaitu dapat meningkatkan daya tarik dan perhatian peserta didik, dengan $\mathrm{CD}$ interaktif ini maka pembelajaran dapat berlangsung secara menarik dan meningkatkan motivasi belajar peserta didik. Penggunaan CD interaktik juga memudahkan bagi guru dalam menyiapkan, mengimplementasikan pembelajaran berbantu media tersebut. Hal tersebut sesuai dengan pendapat Warsita (2008) bahwa keunggulan dari CD interaktif yaitu lebih fleksibel dalam pembuatan dan penggunaan, kegunaan disesuaikan dengan kesiapan masing-masing peserta didik, menyediakan informasi yang lebih banyak dan mendalam, serta bersifat komunikasi dua arah. Dengan demikian, peserta didik akan lebih terangsang dalam proses pembelajaran sehingga tujuan pembelajaran tercapai dan hasil bisa maksimal.

Berdasarkan hasil penelitian di atas, maka disimpulkan penggunaan media CD interaktif dalam proses pembelajaran mata pelajaran PKn pada peserta didik kelas 3 SDN 02 Talun dapat meningkatkan hasil belajar peserta didik. Hal tersebut terlihat dari siklus 1 sebesar 73,68\% dengan peserta didik yang telah mencapai KKM ada 14 orang. Dan pada siklus 2 sebesar $89,47 \%$ dengan peserta didik yang telah mencapai KKM ada 14 orang. Saran yang dapat 
disampaikan dari peneliti adalah agar para guru dapat lebih membiasakan diri dalam pembuatan media interaktif agar proses pembelajaran lebih menarik dan menumbuhkan minat belajar peserta didik. Kemudian untuk semua pihak untuk dapat lebih memperhatikan sarana penunjang bagi guru dan peserta didik agar proses pembelajaran dapat berjalan secara maksimal.

\section{PENUTUP}

Berdasarkan hasil penelitian di atas, maka disimpulkan penggunaan media CD interaktif dalam proses pembelajaran mata pelajaran PKn pada peserta didik kelas 3 SDN 02 Talun dapat meningkatkan hasil belajar peserta didik. Hal tersebut terlihat dari siklus 1 sebesar 73,68\% dengan peserta didik yang telah mencapai KKM ada 14 orang. Dan pada siklus 2 sebesar $89,47 \%$ dengan peserta didik yang telah mencapai KKM ada 14 orang. Saran yang dapat disampaikan dari peneliti adalah agar para guru dapat lebih membiasakan diri dalam pembuatan media interaktif agar proses pembelajaran lebih menarik dan menumbuhkan minat belajar peserta didik. Kemudian untuk semua pihak untuk dapat lebih memperhatikan sarana penunjang bagi guru dan peserta didik agar proses pembelajaran dapat berjalan secara maksimal.

\section{DAFTAR PUSTAKA}

Arifin, Z. (2014). Penelitian Pendidikan Metode dan Paradigma Guru. Bandung: PT Remaja Rosdakarya

Arikunto, S. (2015). Penelitian Tindakan Kelas. Jakarta: Bumi Aksara

Asyhar, R. (2012). Kreatif Mengembangkan Media Pembelajaran. Jakarta. Referensi.

Depdiknas. (2006). Permendiknas No 22 Tahun 2006 Tentang Standar Isi. Jakarta: Depdiknas.

Hayumuti. (2016). Penggunaan Multimedia CD Interaktif dalam Peningkatan Aktivitas dan Hasil Belajar IPA Tema Selalu Berhemat Energi di Kelas IV SDN Klanderan Kediri. Jurnal Pendidikan: Teori, Penelitian, dan Pengembangan. 1(7) 1437-1441

Mulyaningrum, N \& Rivai, A. (2009). Pendidikan Kewarganegaraan unntuk SD/MI Kelas III. Jakarta: Pusat Perbukuan Departemen Pendidikan Nasional.

Rahayuningrum, R. H. (2012). Penggunaan Media Pembelajaran Multimedia Interaktif Berbantuan Komputer untuk Meningkatkan Motivasi Belajar dan Kemampuan Pemecahan Masalah Matematika Siswa Kelas VII-F di SMP Negeri 2 Imogiri Bantul. Makalah LSM XIX Lomba Seminar Matematika, ISBN: 978-979-17763-3-2. (Online),

Sofhian, S. \& Asep, S.G. (2011). Pendidikan Kewarganegaraan (Civic Education. Bandung: Fokus Media.

Sudjana, N \& Rivai, A. (2007). Media Pengajaran. Bandung: Sinar Baru Algensindo.

Suprapto. (2006). Peningkatan Kualitas Pendidikan melalui Media Pembelajaran Menggunakan Teknologi Informasi di Sekolah. Jurnal Ekonomi \& Pendidikan, Volume 3 Nomor 1, April 2006

Warsita, B. (2008). Teknologi Pembelajaran: Landasan \&Aplikasinya. Jakarta: Rineka. 